\title{
Etograma da maria-preta, Molothrus bonariensis (Gmelin) (Aves, Emberizidae, Icterinae)
}

\author{
Gabriele R. Porto ${ }^{1} \&$ Augusto Piratelli ${ }^{2}$ \\ 1 Programa de Pós-graduação em Biologia Animal, Universidade Federal Rural do Rio de Janeiro. Rua General Gerardo Braga \\ 34, Guaratiba, 23036-160 Rio de Janeiro, Rio de Janeiro, Brasil.E-mail: gabrieleporto@uol.com.br \\ 2 Departamento de Biologia Animal, Instituto de Biologia, Universidade Federal Rural do Rio de Janeiro. Rodovia BR 465, \\ Km 7, 23890-000 Seropédica, Rio de Janeiro,Brasil. E-mail: pirateli@ufrrj.br
}

\begin{abstract}
Ethogram of the Shiny Cowbird, Molothrus bonariensis Gmelin (Aves, Emberizidae, Icterinae). The aim of this work is to study behavioral patterns of Molothrus bonariensis (Gmelin, 1789) in natural conditions, drawing its ethogram. Field efforts were carried out in Seropédica, Rio de Janeiro state, Brazil, by means of continuous naturalistic observations and focal-animal, using a 10 x 50 binoculars mainly in the morning until 07:00 $\mathrm{h}$ and in the afternoon after 16:00 h. A total of 25 conducts were detected and grouped in seven behavioral categories: locomotion $(n=7)$, maintenance $(n=5)$, social non-agonistic $(n=5)$, feeding $(n=2)$, social-agonistic $(\mathrm{n}=2)$, vigilance $(\mathrm{n}=2)$ and sonorous $(\mathrm{n}=2)$.
\end{abstract}

KEY WORDS. Behavior, locomotion, maintenance, Rio de Janeiro.

RESUMO. O objetivo deste trabalho foi estudar padrões comportamentais de Molothrus bonariensis (Gmelin, 1789) em condições naturais, traçando seu etograma. As coletas de dados foram efetuadas em Seropédica, no Estado do Rio de Janeiro, através de observações naturalísticas contínuas e animal-focal, utilizando-se binóculos 10 x 50 principalmente pela manhã até às $07: 00 \mathrm{~h}$ e à tarde após as 16:00h. Foram detectadas 25 condutas, agrupadas em sete categorias comportamentais: locomoção $(n=7)$, manutenção $(n=5)$, social não-agonístico $(n=5)$, alimentação $(\mathrm{n}=2)$, social-agonístico $(\mathrm{n}=2)$, vigilância $(\mathrm{n}=2)$ e sonora $(\mathrm{n}=2)$.

PALAVRAS CHAVE. Comportamento, locomoção, manutenção, Rio de Janeiro.

A maria-preta Molothrus bonariensis (Gmelin, 1789) é uma ave parasita de ninhos, tendo perdido tanto a habilidade de fazer o ninho próprio como o instinto de cuidar da prole apresentando comportamento sexual promíscuo (MASON 1987, SicK 1997). Habita paisagens semi-abertas, campos de cultura e pastos e ocorre do Panamá e Antilhas, através da maior parte da América do Sul, até a Argentina e o Chile e em todas as regiões do Brasil (Ridgely \& Tudor 1994, Sick 1997). Recentemente, KluZA (1998) registrou também a ocorrência desta espécie na Península de Yucatan, México. É uma espécie onívora (Machado \& LAMAS 1996), pesando entre 42 e 52 g e medindo entre 16,5 e $21,5 \mathrm{~cm}$; o macho é preto com brilho púrpuro e a fêmea é marrom acinzentada (SICK 1997).

Molothrus bonariensis sincroniza sua postura com a de seus hospedeiros (KATTAN 1997), sendo conhecidos vários casos de aves molestadas por esta espécie, como o tico-tico - Zonotrichia capensis Swainson, 1837 (Emberizidae, Icterinae) (FragA 1978, SICK 1997), o sabiá-laranjeira - Turdus rufiventris Vieillot, 1818 (Turdinae, Muscicapidae) (Di Giacomo \& Aguilar 1987, Lichtenstein 1998), o sanhaço-cinzento - Thraupis sayaca (Linnaeus, 1766) (Emberizidae, Thraupinae) (CAVAlCanti \& Pimentel 1988), o curutié - Certhiaxis cinnamomea (Vieillot, 1817) (Furnariidae) (DiAs \&
MaURício 1997), a viuvinha-Arundinicola leucocephala (Linnaeus, 1764) (Tyrannidae) (SICK 1997), e o tiê-sangue - Ramphocelus bresilius (Linnaeus, 1766) (Emberizidae, Thraupinae) (SICK 1997).

FonERIs (1998) abordou o aspecto reprodutivo ressaltando o parasitismo de M. bonariensis e suas conseqüências em comunidades de aves que ainda não haviam entrado em contato com essa ave. Cavalcanti \& Pimentel (1988) estudaram o parasitismo de $M$. bonariensis em algumas espécies de aves no Brasil central como o sanhaço-cinzento (Thraupis sayaca) e o tico-tico (Zonotrichia capensis), que é uma espécie comum em Brasília e fortemente parasitada. Eles simularam parasitismo artificialmente para estimar quais espécies aceitariam melhor os ovos deste parasita.

O comportamento reprodutivo de $M$. bonariensis afeta o sucesso reprodutivo de seus hospedeiros (MAssoni \& REBOREDA 1998) e varia em intensidade de acordo com as táticas do parasita. Entretanto, o efeito geral do parasita sobre as populações hospedeiras não é muito conhecido (Foneris 1998). Sendo espécie generalista, pode ser favorecida pela degradação ambiental, aumentando suas populações conforme se altera o ambiente. Neste contexto, poderia afetar mais intensamente a reprodução de outras espécies em áreas alteradas. 
Segundo Dias \& Maurício (1997) a maior parte dos trabalhos com esta espécie trata de aspectos morfológicos, ecológicos, distribuição geográfica e parasitismo. Por isso, os estudos sobre comportamento são extremamente importantes para que se conheça melhor sua biologia.

Este trabalho teve como objetivos estudar diversos parâmetros comportamentais de Molothrus bonariensis na natureza, traçando seu etograma e contribuindo, desta forma, com os estudos do comportamento e biologia desta espécie.

\section{MATERIAL E MÉTODOS}

A área de estudo localiza-se no Campus da Universidade Federal Rural do Rio de Janeiro, no município de Seropédica (22044'38"S; 4342'27"W e 26 m de altitude) (Território 2002). O município de Seropédica possui 94,7\% de sua área total $(268,2$ $\mathrm{km}^{2}$ ) dividida em: pastagem $(68,7 \%)$,vegetação secundária $(12,8 \%)$, área urbana $(10,4 \%)$ e área agrícola $(2,8 \%)$ (CoBERTuRA Vegetal 1994, TeRritório 2002).

Um grupo de aproximadamente 300 indivíduos de $M$. bonariensis teve seu comportamento estudado entre agosto de 2000 e julho de 2001 através 32 de sessões quinzenais de observações naturalísticas contínuas e animal-focal (LEHNER 1996). As observações totalizaram 41 horas e foram realizadas com o auxílio de binóculos 10 x 50, principalmente pela manhã das 06:00 até às 07:00 h e à tarde a partir das 16:00 h.

Foram definidas condutas comportamentais agrupadas em categorias comportamentais adaptadas de МiкIcH (1991) e Prestes (2000). A partir das observações, foram elaboradas ilustrações e traçados os etogramas. Para se estimar a abrangência das categorias e condutas detectadas, foi traçada uma curva de coletor para categorias novas.

\section{RESULTADOS}

Foram identificadas e descritas 25 condutas agrupadas em sete categorias comportamentais: manutenção $(n=5)$, locomoção $(n=7)$, alimentação $(n=2)$, social-não-agonística (n $=5)$, social-agonística $(\mathrm{n}=2)$, alerta $(\mathrm{n}=2)$, e sonora $(\mathrm{n}=2)$ :

\section{Manutenção}

Cinco condutas foram identificadas nesta categoria: limpeza das penas das asas, limpeza do bico, limpeza das penas do peito, limpeza das penas do dorso, limpeza das penas das axilas.

Limpeza da penas das asas. A maria-preta, de pé sobre o substrato (taboa, galho de árvore, fio elétrico, telhado) utilizava o bico para limpeza das penas das asas. Com a cabeça voltada para a asa correspondente debicava e, algumas vezes, alisava as penas com o bico (Fig. 1).

Limpeza do bico. A ave passava o bico lateral e alternadamente várias vezes (lado direito-lado esquerdo) contra o substrato, geralmente um poleiro (Fig. 2).

Limpeza das penas do peito. O indivíduo de pé no poleiro, inclinava a cabeça em direção ao peito e debicava ou alisava as penas desta região com o bico (Fig. 3).
Limpeza das penas do dorso. A maria-preta inclinava o pescoço voltando a cabeça para o dorso e debicava ou alisava as penas desta região com o bico, geralmente em pé sobre poleiro (Fig. 4).

Limpeza das penas das axilas. Com uma das asas entreaberta, o indivíduo voltava a cabeça em direção a essa asa, debicava e alisava com o bico alternadamente as penas desta região. Esta conduta foi observada com a ave em pé sobre o poleiro (Fig. 5).

\section{Locomoção}

Identificaram-se sete condutas nessa categoria: vôos curtos, vôos longos, pular batendo as asas, andar no poleiro, pular no poleiro alternando a orientação, subir batendo o bico no galho e dar pulinhos para locomoção lateral.

Vôos curtos. Essa conduta se dava basicamente de duas formas: vôos curtos voltando para o local de partida e vôos curtos mudando de lugar; as duas formas com duração estimada inferior a 30 segundos. Enquanto as aves estavam no dormitório, logo assim que entravam na vegetação de taboa, pouco antes de deixar o dormitório e também durante o dia em galhos ou gramados, observaram-se indivíduos dando vôos batidos curtos e voltando para o local de partida podendo ou não repetir essa conduta várias vezes. Vôos batidos curtos, com o objetivo de mudar de lugar, foram observados no interior da vegetação de taboa e no gramado durante o forrageio. Durante o forrageio e no gramado observou-se um grupo grande que, aleatoriamente, dividia-se em pequenos grupos e utilizavam vôos curtos para deslocamento a curtas distâncias, apenas mudando a posição no gramado (Figs 6-8).

Vôos longos. Para a locomoção do grupo ou individual a longas distâncias, observaram-se vôos longos, alternando-se os padrões de vôo batido e planado; duração estimada superior a 30 segundos (Fig. 9).

Pular batendo as asas. Os indivíduos davam pequenos saltos batendo as asas. Ocorria geralmente quando as aves estavam empoleiradas no ápice da vegetação de taboa pouco antes de cessar a atividade no dormitório ao anoitecer ou ao amanhecer, quando a atividade se intensificava, pouco antes de deixarem o dormitório e em poleiros como galhos de árvore, cercas e fios elétricos (Fig. 10).

Andar no poleiro. A maria-preta andava no poleiro com passos curtos lateralmente, geralmente em resposta a uma aproximação ou afastamento de outro indivíduo (Fig. 11).

Pular no poleiro alternando a orientação. A maria-preta pulava no poleiro alternando a orientação (como se estivesse olhando para frente e para trás, dando meias voltas) locomovendo-se lateralmente com as asas entreabertas (Fig. 12).

Subir batendo bico no galho. Enquanto a maria-preta subia no galho dando pequenos pulos, debicava ao mesmo tempo o galho em questão (Fig. 13).

Dar pulinhos para se locomover lateralmente. O indivíduo em pé no poleiro dava pulinhos para se locomover lateralmente em resposta a uma aproximação ou afastamento de outro indivíduo com o objetivo de aproximar-se ou afastar-se (Fig. 14).

Revista Brasileira de Zoologia 22 (2): 306-312, junho 2005 

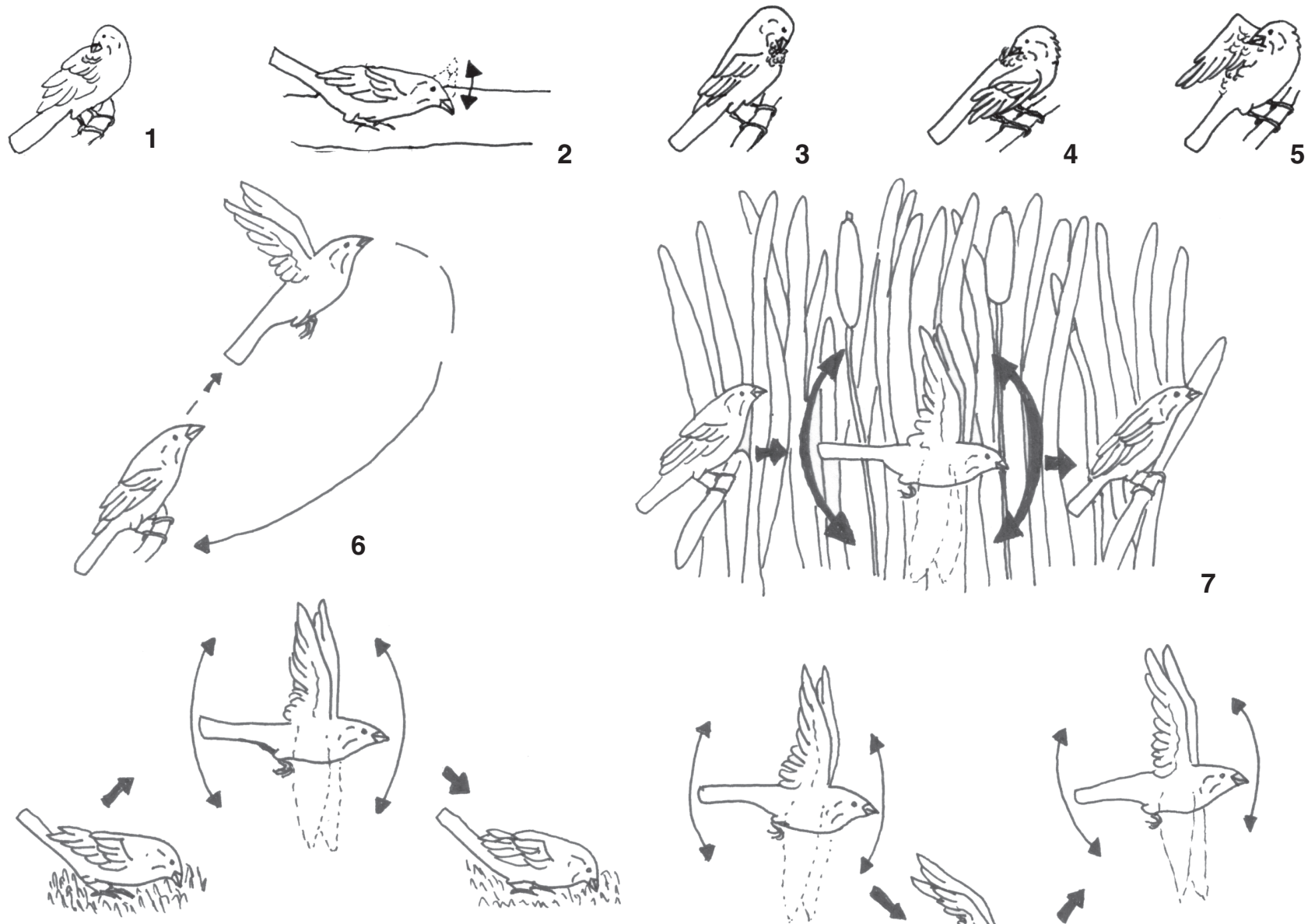

8
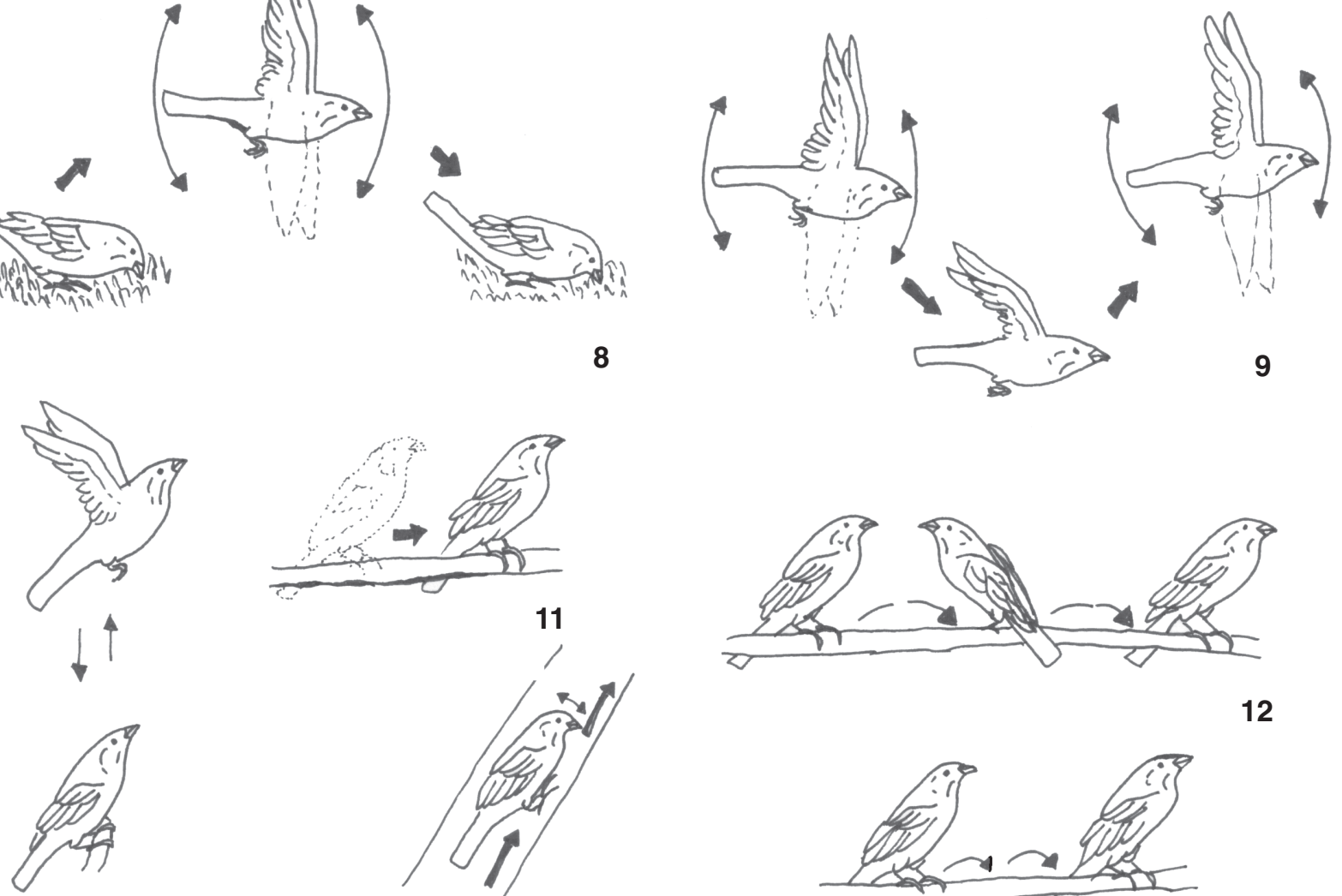

10
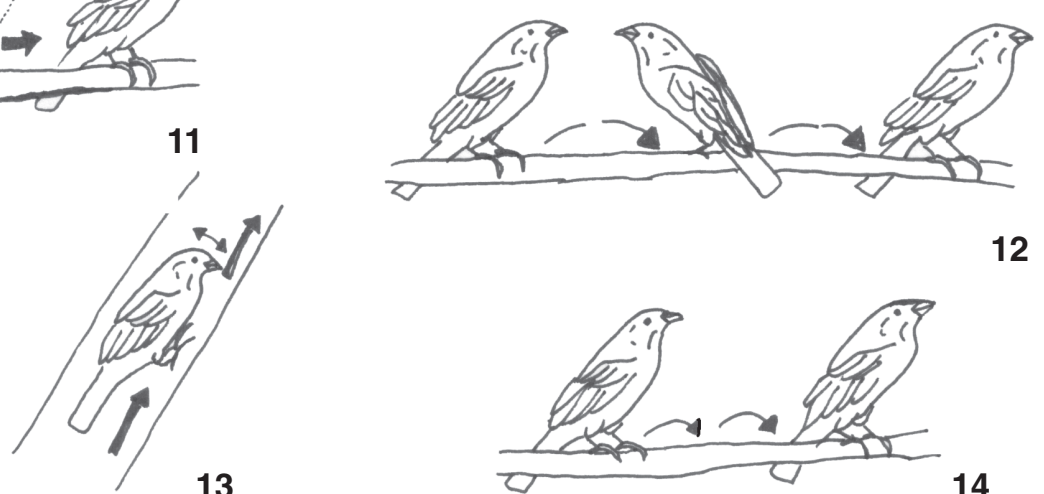

12

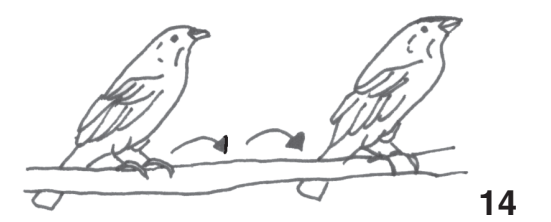

Figuras 1-14. Categorias comportamentais. (1-5) Manutenção: (1) limpeza da penas das asas; (2) limpeza do bico; (3) limpeza das penas do peito; (4) limpeza das penas do dorso; (5) limpeza das penas das axilas; (6-14) locomoção: (6-8) vôos curtos; (9) vôos longos; (10) pular batendo as asas; (11) andar no poleiro; (12) pular no poleiro alternando a orientação; (13) subir batendo bico no galho; (14) dar pulinhos para se locomover lateralmente. 


\section{Alimentação}

Observaram-se duas condutas nessa categoria: comer e beber.

Comer. A ave de pé, bicava, mandibulava e engolia seu alimento (Fig. 15). Essa conduta foi observada geralmente em um gramado próximo ao lago do Instituto de Biologia $\left(22^{\circ} 45^{\prime} 34^{\prime \prime}\right.$; ; $\left.43^{\circ} 41^{\prime} 27^{\prime \prime} \mathrm{W}\right)$ e na Suinocultura $\left(22^{\circ} 46^{\prime} 38^{\prime \prime}\right.$; $43^{\circ} 39^{\prime} 54^{\prime \prime} \mathrm{W}$ ) da Universidade Rural. Os bandos de forrageamento eram constituídos de cerca de 20 indivíduos; porém, à tardinha e, particularmente após a poda do gramado por tratores, grupos de até 300 indivíduos puderam ser observados, sem quaisquer interações agonísticas. No segundo local, observou-se em uma ocasião um grupo pequeno (10 indivíduos) comendo restos de ração suína, caracterizando o comportamento alimentar desta espécie como altamente generalista e oportunista. Grupos de cerca de até 300 indivíduos ocorriam aparentemente quando motivados por eventos particulares como a poda do gramado, que acarretava grande movimentação de artrópodos que nele se encontravam, gerando uma ocasião de maior oferta de alimentos, possibilitando a formação de grandes agregações, sem ocorrência de interações agonísticas.

Beber água. Conduta observada em vegetação de taboa do Instituto de Biologia da Universidade Rural. A ave de pé sobre o poleiro inclinava o corpo para frente e esticava o pescoço de forma que seu bico alcançava a lâmina d'água; rapidamente, levantava o pescoço esticado para cima, engolindo a água. Esses movimentos eram realizados repetidas vezes (Fig. 16).

\section{Social-não-agonístico}

Foram identificadas cinco condutas nessa categoria: agrupamento-aproximação, agrupamento-afastamento, relações interespecíficas, chegada ao dormitório e saída do dormitório.

Agrupamento-aproximação. A aproximação entre os indivíduos se dava de várias maneiras: por meio de vôos, andando ou saltando. Um indivíduo se aproximava do outro desde que este aceitasse ou não percebesse sua proximidade. Os indivíduos chegavam à área de dormitório em pequenos grupos que se uniam em locais próximos à taboa, árvores e gramado, formando grupos maiores. Depois de formados os grupos maiores em árvores próximas ao dormitório, estes entram na vegetação de taboa do lago do Instituto de Biologia da Universidade Rural. (Figs 17 e 21).

Agrupamento-afastamento. O afastamento assim como o agrupamento podia ocorrer por meio de vôos, andando ou saltando (geralmente para os lados). Uma ave afastava-se da outra sem motivos aparentes, ou por não aceitar sua proximidade. Enquanto um macho se aproxima do outro no mesmo galho, o segundo ia se afastando com pequenos pulos laterais até voar, geralmente seguido do primeiro. Uma fêmea em pé no poleiro se locomovia lateralmente com pequenos pulos, enquanto o macho tentava aproximar-se andando lateralmente. A fêmea afastava-se até que voava; o macho permanecia no poleiro limpando suas penas e posteriormente voava também (Figs 18-20). Essa conduta também foi observada com objetivo de afastar-se de algo que se apresentasse como uma potencial ameaça ao bando. Um grupo de marias-pretas forrageando no gramado, ao perceber a aproximação humana voava, interrompendo a atividade de forrageio e pousando em árvores próximas, até que pudesse voltar para o gramado.

Relações interespecíficas. A maria-preta compartilhava os dormitórios com garibaldos (Agelaius ruficapillus)e lavadeiras (Arundinicola leucocephala) (Figs 21 e 22), não tendo sido observadas agressões entre essas espécies. Sıck (1997) cita casos em que a maria-preta parasita os ninhos destas espécies porém esse comportamento não foi aqui observado.

Chegada ao dormitório. O dormitório utilizado pelas marias-pretas era a vegetação de taboa (Typhaceae) encontrada no lago do Instituto de Biologia (22 $45^{\prime} 34^{\prime \prime}$; $\left.43^{\circ} 41^{\prime} 27^{\prime \prime} \mathrm{W}\right)$ e no lago da EMBRAPA $\left(22^{\circ} 45^{\prime} 35^{\prime \prime}\right.$; $43^{\circ} 41^{\prime} 05^{\prime \prime} \mathrm{W}$ ) (distantes 630 $\mathrm{m}$ entre si), no campus da Universidade Federal Rural do Rio de Janeiro. Por volta das 16:00h as marias-pretas começavam a chegar ao dormitório individualmente, em pequenos grupos (2 a 20) ou em grupos grandes (40 a 60) que ora entravam diretamente na vegetação de taboa, ora reuniam-se em árvores próximas, formando grupos maiores e então entravam na vegetação de taboa (Fig. 21); vocalizando e dando vôos curtos, saltando e voltando para o mesmo local.

Saída do dormitório. Por volta das 06:15 h começava a vocalização, que se intensificava aproximadamente às 06:20h. Intensificava-se também a movimentação dos indivíduos, que começavam a dar curtos vôos ou pulos batendo as asas individualmente ou em pequenos grupos. Essas aves dormiam no terço inferior da vegetação de taboa e, ao amanhecer, começavam a migrar para a porção superior, de onde se iniciavam os pequenos vôos e pulos. Alguns grupos sobrevoavam a vegetação de taboa e entravam na taboa novamente, saindo e voltando. As marias-pretas saiam em pequenos grupos que voavam diretamente em várias direções ou que antes se reuniam nas árvores próximas para posteriormente voar para os locais de forrageio (Fig. 22).

\section{Social-agonístico (agressões)}

Identificaram-se duas condutas nessa categoria: agressões interespecíficas e agressões intraespecíficas.

Agressões interespecíficas. Foram observados dois machos de maria-preta perseguindo um bem-te-vi - Pitangus sulphuratus (Linnaeus, 1766) (Tyrannidae) - bicando-o durante um vôo curto (Fig. 23) por este ter invadido a área onde um grupo de marias-pretas estava forrageando.

Agressões intraespecíficas. Ocorriam por disputa de lugar no substrato de pouso. Um macho que alcançava primeiro o galho não deixava que o outro pousasse, eriçando as penas da cabeça e do dorso, pulando batendo as asas, vocalizando e tentando bicar o outro macho, que era obrigado a continuar voando até encontrar outro galho (Fig. 24). 

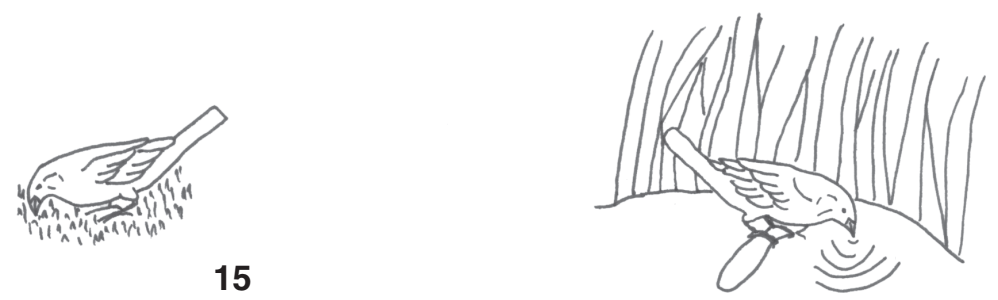

15

16
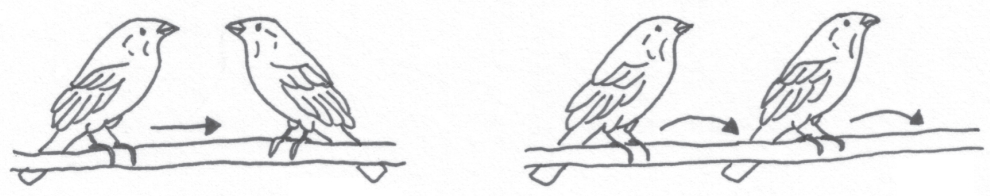

17
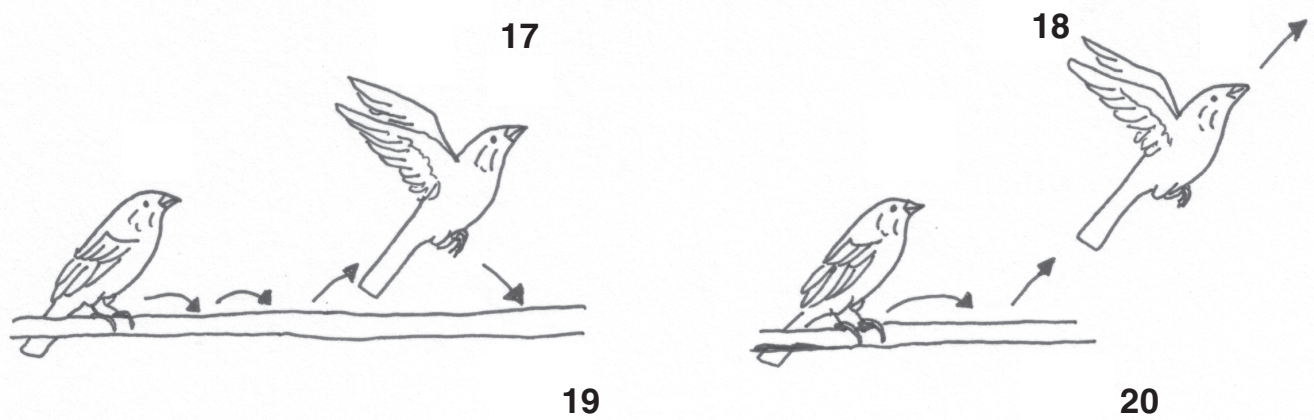

19

20

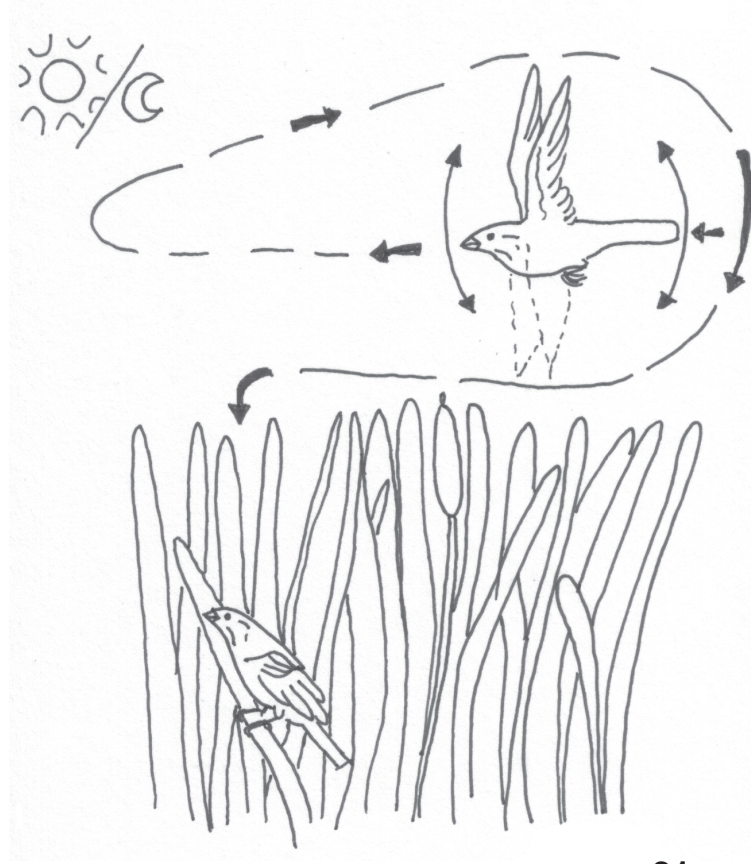

21

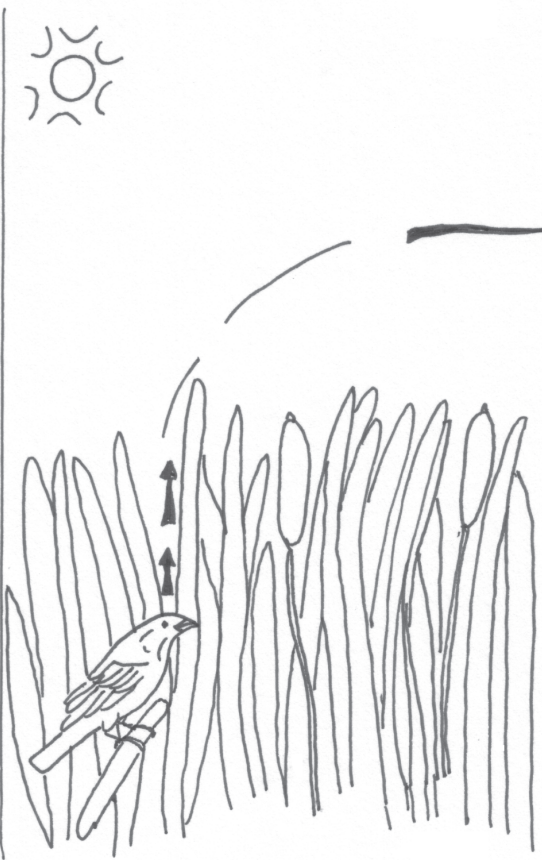

22

Figuras 15-22. Categorias comportamentais. (15-16) alimentação: (15) comer; 16) beber água; (17-22) social-não-agonística: (17, 21) agrupamento-aproximação; (18-20) agrupamento-afastamento; (21) chegada ao dormitório; (22) saída do dormitório; (21-22) relações interespecíficas.

Revista Brasileira de Zoologia 22 (2): 306-312, junho 2005 

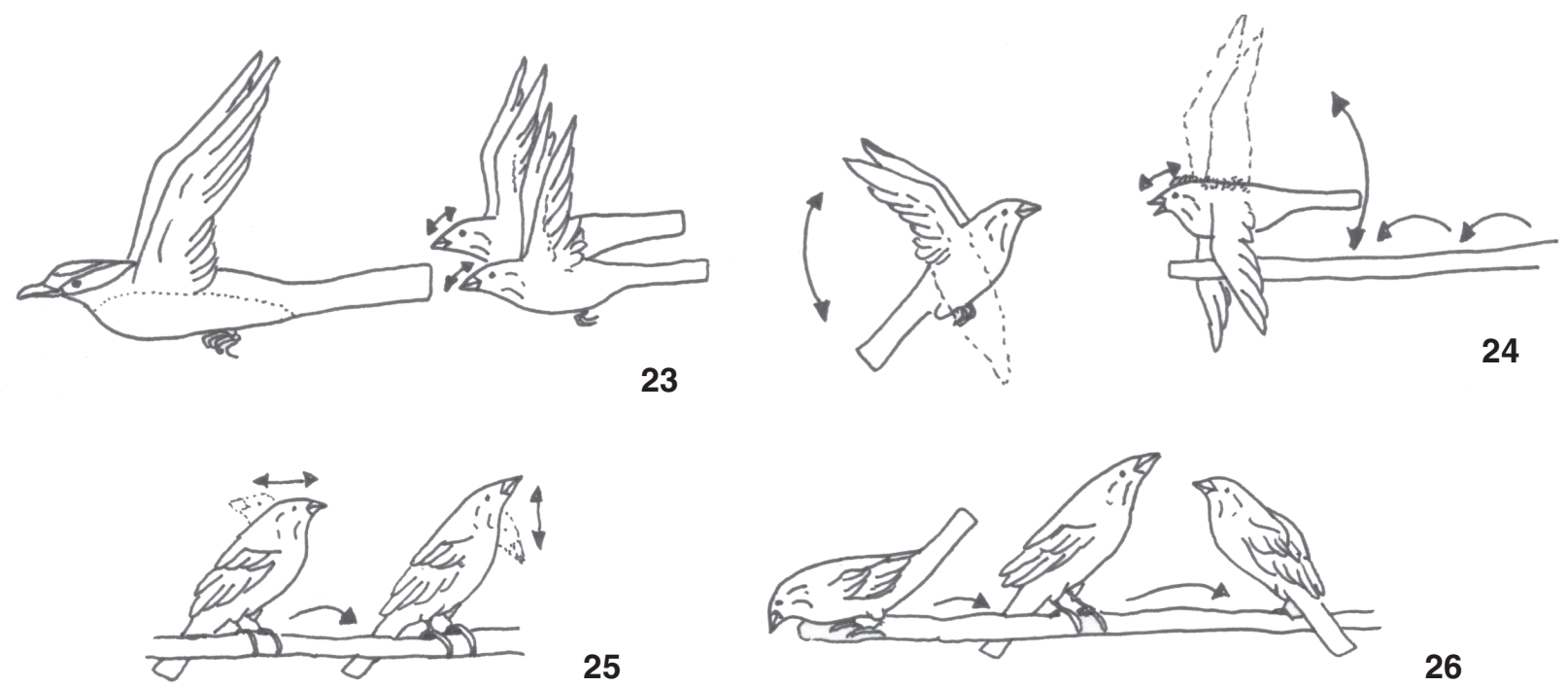

25

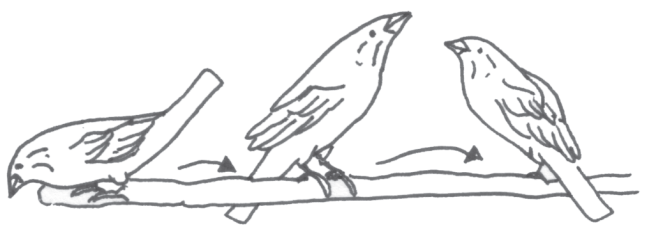

26

Figuras 23-24. Categorias comportamentais. (23-24) social-agonístico (agressões): (23) agressões interespecíficas; (24) agressões intraespecíficas; (25-26) alerta: (25) orientar a cabeça; (26) sentinela.

\section{Alerta}

Foram reconhecidas duas condutas nesta categoria: orientar a cabeça e sentinela.

Orientar a cabeça. A cabeça era orientada para os lados com movimentos ora lentos ora rápidos e contínuos, com a ave em pé no poleiro (Fig. 25).

Sentinela. A ave assumia várias posições em que observava atentamente os arredores, movimentando rapidamente a cabeça. Geralmente a ave ficava de pé no poleiro com o pescoço esticado (Fig. 26).

\section{Sonora}

Foram detectados dois tipos de comunicações sonoras: vocalização crepuscular/matinal e vocalização agonística.

Vocalização crepuscular/matinal. Crepuscular: iniciavase por volta das $16: 30 \mathrm{~h}$, assim que a maioria dos grupos de marias-pretas estava no interior do dormitório preparando-se para dormir. A vocalização se intensificava com o entardecer e aos poucos ia diminuindo até cessar com o anoitecer, até aproximadamente às 18:00h. A vocalização matinal era semelhante à crepuscular, iniciava-se ao amanhecer por vota das 06:15h, quando as aves que estavam no dormitório e começavam a despertar, intensificando-se por volta das 06:25h e cessando a medida em que as marias-pretas deixavam o dormitório, aproximadamente às 07:00h.

Vocalização agonística. Dá-se durante as agressões.

Conforme a curva de coletor, provavelmente não seriam elucidadas novas condutas comportamentais com a continuidade das observações, uma vez que a curva se estabilizou antes do final das coletas (Fig. 27).Vale ressaltar que não foram estudados aspectos do comportamento reprodutivo e, neste caso, novas condutas poderiam ser observadas.

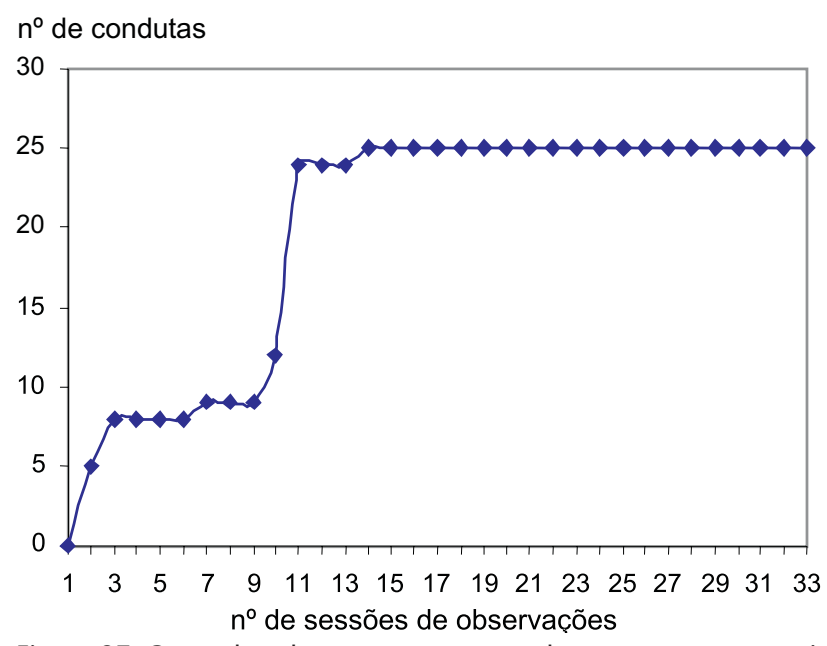

Figura 27. Curva de coletor para novas condutas comportamentais de $M$. bonariensis em relação ao número de sessões de observações no campus da Universidade Federal Rural do Rio de Janeiro, Seropédica, Rio de Janeiro.

\section{DISCUSSÃO E CONCLUSÕES}

Todas as categorias comportamentais descritas por PrESTES (2000) em seu trabalho com Amazona pretrei (Temminck, 1830) (Psitacidae) foram identificadas também para a mariapreta; porém somente as condutas de limpeza, andar, voar, saltar, comer, agrupamento-aproximação, agrupamento-afastamento, briga (agressão) e alerta são comuns às duas espécies.

Мікісн (1991), em seu trabalho com Ramphastos toco (Statius Muller, 1776) (Ramphastidae), utilizou categorias

Revista Brasileira de Zoologia 22 (2): 306-312, junho 2005 
comportamentais e complexos comportamentais para definir o que foi descrito em Prestes (2000) e no presente trabalho como condutas comportamentais e categorias comportamentais respectivamente. A maria-preta apresentou em comum com $R$. toco a categoria de manutenção (conduta de coçar-se com o bico - semelhante à limpeza das penas em M. bonariensis) e a categoria comportamental alerta (conduta orientar a cabeça).

A espécie estudada aproveita-se de ações antrópicas para alimentação (poda de gramados com tratores, rações para animais de criação) e abrigo (lagos artificiais com taboa), executando diversas condutas comportamentais que sugerem uma rápida adequação às condições do ambiente.

\section{AGRADECIMENTOS}

Ao PIBIC/CNPq, Universidade Federal Rural do Rio de Janeiro, pela bolsa de Iniciação Científica concedida à primeira autora durante as coletas de dados e à Capes pela bolsa de mestrado durante a redação deste trabalho; a Everton F. Oliveira e Juliana Corrêa, pelo apoio nas observações, à Daniele F. Moura e Alex da Silva Sirqueira, pelo auxílio na digitação e a Daniel de Brito Corrêa Santos pela ajuda na revisão deste trabalho; aos Drs Ildemar Ferreira e Pedro E.C. Ventura, pelo incentivo e sugestões.

\section{REFERÊNCIAS BIBLIOGRÁFICAS}

Cavalcanti, R.B. \& T.M. Pimentel. 1988. Shiny Cowbird parasitism in central Brazil. Condor, Santa Clara, 90 (1): 40-43.

Cobertura Vegetal. 1994. Percentual das áreas por tipo de uso de solo, segundo os municípios - Estado do Rio de Janeiro. Disponível na World Wide Web: http://www.cide.rj. gov.br/bancodados/iqmverde.htm. Acesso em 17/IX/2003.

DiAs, R.A. \& G.N. Maurício. 1997. Certhiaxis cinnamomea como hospedeiro de Molothrus bonariensis no Sul do Brasil. Atualidades Ornitológicas, Ivaiporá, 79: 9.

Di Giacomo, A.G. \& H.A. Aguilar. 1987. Sobre um nuevo hospedante para la Argentina del renegrido Molothrus bonariensis (Aves: Icteridae). Nótulas Faunísticas, Corrientes, 4: 2.

Foneris, L. 1998. Gaudério, agente de extinção e ameaça à avifauna? Boletim do CEO, São Paulo, 13: 24-27.

FraGA, R.M. 1978. The Rufous-collared Sparrow as host of the Shiny Cowbird. Wilson Bulletin, Ann Arbor, 90 (20): 271284.

KatTan, G.H. 1997. Shiny Cowbirds follow the 'shotgun' strategy of brood parasitism. Animal Behavior, Londres, 53 (3): 647654.

KLuZA, D.A. 1998. First record of Shiny Cowbird (Molothrus bonariensis) in Yucatán, Mexico. Wilson Bulletin, Albuquerque, 110 (3): 429-430.

Lehner, P.N. 1996. Handbook of ethological methods. Cambridge, Cambrigde University Press, 672p.

Lichtenstein, G. 1998. Parasitism by shiny cowbirds thrushesof rufous-bellied. Condor, Santa Clara, 100 (4): 680-687.

Machado, R.B. \& I.R. LAMAs. 1996. Avifauna associada a um reflorestamento de eucalipto no município de Antônio Dias (MG). Ararajuba, Belo Horizonte, 4 (1): 15-22.

Mason, P. 1987. Pair Formation in Cowbirds; Evidence Found for Screaming but not Shiny Cowbirds. Condor, Santa Clara, 89 (2): 349-356.

Massoni, V. \& J.C. Reboreda. 1998. Costs of brood parasitism and the lack of defenses on the Yellow-winged Black Bird Shiny Cowbird system. Behavioral Ecology and Sociobiology, Heidelberg, 42 (4): 273-280.

Мiкich, S.B. 1991. Etogama de Ramphastos toco em cativeiro (Piciformes: Ramphastidae). Ararajuba, Rio de Janeiro, 2: 3-17.

PRESTES, N.P. 2000. Descrição e análise quantitativa do etograma de Amazona petrei em cativeiro. Ararajuba, Londrina, 8 (1): 25-42.

Ridgely, R. S. \& G. Tudor. 1994. The birds of South America. The Oscine Passerines. Austin, University of Texas Press, vol. 2, 516p.

SICK, H. 1997.Ornitologia brasileira. Rio de Janeiro, Editora Nova Fronteira, 862p.

TERRITÓRIO. 2002. Altitude e área total, segundo as regiões de governo e municípios do Rio de Janeiro. Rio de Janeiro, Disponível na World Wide Web: http://www.cide.rj.gov.br/ bancodados/territorio.htm. Acesso em 17/IX/2003.

Recebido em 31.V.2004; aceito em 30.IV.2005. 